\title{
Minimally Invasive Sacroiliac Joint Fusion: The Current Evidence
}

\author{
CHRISTOPHER T. MARTIN, MD, ${ }^{1}$ LUCAS HAASE, BA, ${ }^{2}$ PAUL A. LENDER, BS, ${ }^{1}$ DAVID W. POLLY JR, \\ $\mathrm{MD}^{1}$ \\ ${ }^{I}$ Department of Orthopaedic Surgery, University of Minnesota, Minneapolis, Minnesota, ${ }^{2}$ University of Minnesota Medical School, Minneapolis, Minnesota
}

\begin{abstract}
Background: Fusion of the sacroiliac (SI) joint as a treatment for low back pain remains controversial. The purpose of this manuscript is to review the current literature and clinical outcomes of SI joint fusion surgery.

Methods: We conducted a literature review and included studies with the term "sacroiliac joint fusion" that had at least 12 months of clinical follow-up, reported on minimally invasive techniques, and included patient-reported outcome measures.

Results: Two approach types (dorsal and lateral) and numerous different implant manufacturers were identified. Most studies included level 4 data, with a small number of level 2 prospective cohort studies and 2 prospective level 1 studies. Every reviewed study reported clinical benefit in terms of improved pain scores or improvement in validated disability measures. Complication rates were low.

Conclusions: Minimally invasive SI joint fusion provides clinically significant improvement in pain scores and disability in most patients, across multiple studies and implant manufacturers.

Level of Evidence: 5

Clinical Relevance: Emerging evidence in support of SI joint fusion indicates that clinicians should examine the SI joint and include SI joint pain in their differential diagnosis for low back pain patients.

Minimally Invasive Surgery

Keywords: back pain, biomechanics, evidence, outcomes, sacroiliac joint fusion, SI fusion, review
\end{abstract}

\section{INTRODUCTION}

The annual prevalence of low back pain among adults ranges from $15 \%$ to $45 \%$ and is among the most common reasons for a physician visit in the United States. ${ }^{1}$ The economic impact is tremendous, with an estimated annual expenditure of $\$ 85$ billion in $2005,{ }^{2}$ and multiple studies showing trends towards increasing expenditure over time. ${ }^{1,3}$ In spite of this expenditure, the health outcomes and population-level disability related to low back pain do not seem to be declining, and some health policy makers have questioned the value and efficacy of current medical treatments. ${ }^{2}$

In response to this burden of disease, and in the hopes of improving outcomes, significant efforts have been made to better understand the various etiologies of back pain. In particular, increasing attention has recently been given to the SI joint as a pain generator, and estimates of low back pain attributable to the SI joint range from $15 \%$ to $30 \%{ }^{4,5}$ Studies have shown that the SI joint both has motion ${ }^{6-8}$ and is innervated, ${ }^{9-11}$ the combination of which bolsters the argument in favor of the joint as a possible pain generator. In spite of this prevalence, many clinicians do not routinely examine the SI joint or include it as a possible pain generator in their differential diagnosis, which may contribute to poor clinical outcomes and wasted health care expenditure. ${ }^{12}$

The purpose of this review is to summarize the clinical outcome studies related to minimally invasive SI joint fusion. A review of this information should familiarize clinicians with the various implant types and the evidence available for each.

\section{MATERIALS AND METHODS}

We conducted a PubMed search for articles with the term "sacroiliac joint fusion" and identified 325 articles on September 2, 2018. Articles were then excluded if they included follow-up shorter than 12 months, were focused on nonsurgical treatment or on non-fusion-based treatments, were primarily focused on open surgical treatment as opposed to 
minimally invasive, reported on revision surgeries instead of primary cases, were non-English-language manuscripts, or if they reported on nonhuman subjects. Papers were also excluded if they had no validated clinical outcome measures (specifically visual analog scale [VAS] or Oswestry Disability Index [ODI] scores). The first author of this manuscript then reviewed each abstract for relevancy. Relevant manuscripts were then organized according to surgical approach, level of evidence, and implant type. Where available, we then pooled the preoperative and postoperative VAS pain scores and ODI scores. In some studies the VAS was reported on a scale from 0 to 10 , and in others it was reported from 0 to 100 . In studies that used a scale of 0 to 10 , we simply multiplied the number by 10 to produce a uniform scale across all of the studies. We calculated weighted means and averages for each data point from each study, and the data were then presented both as a forest plot and also as bar graphs of the combined data. Means were calculated by OpenMeta meta-analysis software using the DerSimonian-Laird method in a continuous random effects model. Studies that reported only a mean but did not include standard deviations could not be included in this analysis because the calculation of a pooled mean requires standard deviation data for each included study.

\section{RESULTS \\ Comparison to Open Fusions}

Open SI joint fusion has been performed since the 1920 s but is no longer the preferred approach to SI joint fusion because of its invasiveness and long recovery periods. ${ }^{13}$ Several comparisons of minimally invasive (MIS) SI joint fusion and open SI joint fusion have been reported.

Smith et $\mathrm{al}^{14}$ compared results of open SI joint fusion $(n=149)$ versus minimally invasive SI joint fusion using triangular titanium implants $(\mathrm{n}=114)$. Patients undergoing minimally invasive surgery were, on average, about 11 years older and more commonly had a history of prior lumbar fusion $(23.5 \%$ versus $47.4 \%)$. Bilateral SI joint fusion was more common in patients undergoing minimally invasive surgery. Compared with open fusion, minimally invasive SI joint fusion was associated with shorter operative times (70 versus 163 minutes), lower estimated blood loss (33 versus $288 \mathrm{~mL}$ ), and lower hospital length of stay (1.3 versus 5.1 days, all comparisons $P<.0001)$. Operative complications occurred in $21 \%$ and $18 \%$ of the open and minimally invasive groups. At 12 months, pain scores improved by 2.7 points in the open group and 6.2 points in the minimally invasive group. The $2-$ year pain scores (available in only 96 patients) showed improvement of 2 points in the open group and 5.6 points in the minimally invasive group. Controlling for age, sex, and other parameters, the difference in pain score improvement was 3 points higher in the MIS group. Limitations to this study include the nonrandomized comparison and confounding by physician (in most cases, the surgeons performing open SI joint fusion were different from those performing minimally invasive SI joint fusion).

Ledonio et $\mathrm{a}^{15}$ compared operative and postoperative outcomes of 36 patients who underwent open SI joint fusion with 27 patients who underwent minimally invasive SI joint fusion at the same center. Using propensity score matching on age, sex, body mass index, and history of spine fusion, analysis was done on 44 of 63 patients $(70 \%$; 22 in each group, open and minimally invasive SI joint fusion). Mean follow-up was 13 (open patients) and 15 (minimally invasive patients) months. Blood loss was higher in the open group (681 versus $41 \mathrm{~mL}$, $P<.0001)$. Mean surgical time was higher in the open group (128 versus 68 minutes) and hospital length of stay was higher (3.3 versus 2 days). ODI scores improved from 62 at baseline to 47 (open) and 54 (minimally invasive). Mean ODI improvements were 19.8 and 12 points. Three complications were reported in the open group: pulmonary embolism and 2 revisions for failed implant and nerve root irritation. Three complications occurred in the minimally invasive group, including 1 pulmonary embolism and 2 revisions. The study noted that it was underpowered for some comparisons.

Ledonio et $\mathrm{al}^{16}$ report a comparison of 22 open and 17 minimally invasive SI joint fusions using triangular titanium implants at 2 institutions. Patient participants undergoing open SI joint fusion overlap with the previous publication, whereas the 17 minimally invasive SI joint fusions were from Cummings and Capobianco. Data were unavailable from 10 additional patients. Patients undergoing minimally invasive SI joint fusion were more than 10 years older. Surgical time was longer in the open group (128 versus 27 minutes) and hospital stay was 
also longer ( 3 days versus 1 day, both comparisons $P<.0001$ ). ODI improved from (median) 64 to 46 in the open group and 53 to 13 in the minimally invasive group. The ODI change was larger for the minimally invasive group by a median of 9 points.

\section{Patient-Reported Outcomes of MIS SI Joint Fusions}

There are 2 published approaches for minimally invasive SI joint fusion; dorsal or lateral transiliac. There are also reports of open dorsal, lateral, and anterior fusion techniques, but these manuscripts are outside the scope of this article, because we chose to focus the review on minimally invasive cases.

\section{Dorsal Approach}

The dorsal approach is performed through a dorsal midline or paramedian incision with dissection to the dorsal ligamentous recess between the sacrum and ilium. The soft tissues of the joint are debrided, and then an implant and bone graft material are placed.

One retrospective series documents the clinical outcomes of a dorsal minimally invasive approach to SI joint fusion. Endres and Ludwig ${ }^{17}$ describe 19 patients with a hollow threaded fusion cage (DIANA cage, Signus, Alzenau, Germany). Intraoperative blood loss was less than $150 \mathrm{cc}$ in all cases. The average length of stay was 7.3 days. Mean VAS SI joint pain scores decreased from 8.5 at baseline to 6 at final follow-up (mean, 13.2 months). Mean ODI score decreased from 64.1 at baseline to 57 at follow-up. Fusion, defined as lack of loosening around the implants and bone bridging across the joint, was seen in $79 \%$ of joints.

Wise and Dall ${ }^{18}$ published a prospective study in 2008 on 13 consecutive patients who underwent MIS SI fusion using threaded fusion cages filled with rhBMP-2. The mean follow-up period for all 13 patients was 29.5 months (range, 24-35 months). Significant improvements were seen in final low back pain score on a VAS, with an average improvement of $4.9(P<.001)$. Leg pain improved an average of 2.4 points $(P=.013)$, and dyspareunia pain improved an average of 2.6 points $(P=.0028)$. The mean estimated blood loss was less than 100 $\mathrm{mL}$; there were no infections or neurovascular complications. The overall fusion rate was $89 \%$ (17 of 19 joints) as assessed by postoperative computed tomography (CT) scan obtained 6 months after the procedure. One patient was revised to an open arthrodesis secondary to nonunion and persistent pain. ${ }^{18}$

Fuchs and Ruhl, ${ }^{19}$ in a level 2 prospective observational study, reported on 171 patients who underwent distraction arthrodesis using the DIANA cage. The study involved 20 hospitals in Germany. Overall patient satisfaction was surveyed along with multiple patient outcome measures. Bony fusion of the SI joint was evaluated using X-ray and CT. The ODI improved from 51 to 33, the SF-MPQ decreased from $50 \%$ to $31 \%$, the SF-12 physical component summary rose from $22 \%$ to $41 \%$, the mental component summary increased from $40 \%$ to $55 \%$, and pain as measured by the VAS decreased from 74 to 37 points (all comparisons $P<.001$ ). In the follow-up CT scans $31 \%$ of the patients showed SI joint fusion, which is a lower rate compared with some of the other approaches described above.

\section{Lateral Transiliac Approach}

Most published series on fusion outcomes use a lateral transiliac approach to try and fix the ilium to the sacrum. The surgery involves dissection through the lateral gluteus musculature down to the table of the ilum and then insertion of a device to transfix the ilium and sacrum together across the SI joint.

\section{Triangular Titanium Implant (SI Bone IFUSE)}

There are 11 level 4 retrospective case series reporting outcomes of the SI Bone IFuse Triangular titanium implant system for MIS SI joint fusions, with 278 unique patients (Table). Each of these are level 4 studies, and the follow-up and use of validated outcome measures are somewhat variable across the studies. The authors of these publications report high rates of patient satisfaction and improvement in pain.

There are 2 level 2 prospective cohort studies with this implant. Duhon et $\mathrm{al}^{32}$ reported 24-month follow-up of a prospective, multicenter single-arm study of 172 patients. The 24-month follow-up rate was $86.6 \%$. SI joint pain decreased from 79.8 at baseline to 26.0 at 24 months $(P<.0001$ for change from baseline). ODI decreased from 55.2 at baseline to 30.9 at 24 months $(P<.0001$ for change from baseline). The proportion of patients taking opioids for SI joint or low back pain decreased from $76.2 \%$ at baseline to $55.0 \%$ at 24 months $(P<.0001)$. A total of 8 patients $(4.7 \%)$ underwent revision SI joint surgery. Seven device-related adverse events 
Table. Summary of level 4 studies on triangular titanium implants.

\begin{tabular}{|c|c|c|c|c|c|}
\hline Source, year & $\begin{array}{l}\text { No. of } \\
\text { Patients }\end{array}$ & $\begin{array}{l}\text { Minimum } \\
\text { Follow-up, } \\
\text { mo }\end{array}$ & Outcomes & Notes & Complications \\
\hline Rudolf, ${ }^{20} 2012$ & 50 & 24 & ODI, SF-36 & $\begin{array}{l}71 \% \text { experienced clinically } \\
\text { significant improvement in } \\
\text { ODI at } 12 \text {-mo follow-up. }\end{array}$ & $\begin{array}{l}10 \text { patients ( } 4 \text { infection/ } \\
\text { wound issues, } 1 \\
\text { fracture, } 2 \text { hematoma, } \\
3 \text { implant malposition) }\end{array}$ \\
\hline $\begin{array}{l}\text { Sachs and Capobianco, }{ }^{21} \\
2012\end{array}$ & 11 & 12 & VAS score & $\begin{array}{l}\text { All also reported in Sachs and } \\
\text { Capobianco. }{ }^{23} \text { Mean VAS } \\
\text { decrease of } 6.2 \text { points. }\end{array}$ & None \\
\hline Rudolf, $^{22} 2013$ & 40 & 24 & Numeric pain scale & $\begin{array}{l}\text { All patients also reported in } \\
\text { Rudolf. }{ }^{20} \text { Both patients with } \\
\text { a prior lumbar fusion and } \\
\text { those without reported pain } \\
\text { relief. }\end{array}$ & $\mathrm{N} / \mathrm{A}$ \\
\hline $\begin{array}{l}\text { Sachs and Capobianco, }{ }^{23} \\
2013\end{array}$ & 40 & 12 & VAS score & $\begin{array}{l}\text { Patients included in Sachs et } \\
\mathrm{al}^{27} \text { multicenter study. Mean } \\
7.8 \text {-point VAS decrease. }\end{array}$ & None \\
\hline $\begin{array}{l}\text { Cummings and } \\
\text { Capobianco, } \\
2013\end{array}$ & 18 & 12 & ODI, SF-36 & $\begin{array}{l}\text { Patients included in Sachs et } \\
\mathrm{al}^{27} \text { multicenter study. Mean } \\
\text { ODI decrease of } 37 \text { points, } \\
\text { clinically significant } \\
\text { improvement in SF- } 36 \text {. }\end{array}$ & $\begin{array}{l}1 \text { fluid retention, } 3 \\
\text { trochanteric bursitis, } 1 \\
\text { toe numbness, } 1 \\
\text { hematoma, } 1 \text { implant } \\
\text { malposition }\end{array}$ \\
\hline Gaetani et al, ${ }^{25} 2013$ & 10 & 8 & ODI, VAS, RMD & $\begin{array}{l}\text { Mean ODI improvement of } 19 \\
\text { points, VAS } 3 \text { points, RMD } \\
14.6 \text { points. }\end{array}$ & 2 hematoma \\
\hline Schroeder et al, ${ }^{26} 2014$ & 6 & 10 & VAS, SRS22, ODI & $\begin{array}{l}\text { Describes SI fusions in } \\
\text { patients with prior long } \\
\text { thoracolumbar fusion for } \\
\text { deformity. Mean } \\
\text { improvement was seen in all } \\
3 \text { outcome measures. }\end{array}$ & \\
\hline $\begin{array}{l}\text { Sachs et al, }{ }^{27} 2014 \\
\text { multicenter }\end{array}$ & 144 & 12 & VAS score & $\begin{array}{l}\text { Includes Cummings and } \\
\text { Capobianco }{ }^{24}(18) \text { and } \\
\text { Sachs and Capobianco } 23 \\
\text { (40). Mean VAS score } \\
\text { decrease of } 5.9 \text { points. }\end{array}$ & 1 implant malposition \\
\hline $\begin{array}{l}\text { Rudolf and Capobianco, }{ }^{28} \\
2014\end{array}$ & 17 & 60 & No validated measure & $\begin{array}{l}\text { Patients are from the original } \\
50 \text { in Rudolf. }{ }^{20} \text { Reported } \\
\text { that } 88 \% \text { received clinical } \\
\text { benefit and } 87 \% \text { were fused } \\
\text { on CT scan. }\end{array}$ & $\begin{array}{l}1 \text { hematoma, } 1 \text { deep } \\
\text { infection, } 1 \text { cellulitis }\end{array}$ \\
\hline $\begin{array}{l}\text { Vanaclocha-Vanaclocha } \\
\text { et al, }{ }^{29} 2014\end{array}$ & 24 & 12 & VAS, ODI & $\begin{array}{l}\text { Mean ODI improvement of } 40 \\
\text { points at } 12 \text {-mo follow-up. }\end{array}$ & None \\
\hline Sachs et al, ${ }^{30} 2016$ & 107 & 36 & VAS score & $\begin{array}{l}\text { Includes patients reported in } \\
\text { Sachs and Capobianco. }{ }^{23} \\
\text { Mean } 4.8 \text { improvement in } \\
\text { VAS. }\end{array}$ & $\begin{array}{l}5 \text { patients required a } \\
\text { revision surgery within } \\
3 \mathrm{yr}\end{array}$ \\
\hline Kancherla et al, ${ }^{31} 2017$ & $\begin{array}{l}36 \text { iFuse, } \\
9 \text { Samba Screw }\end{array}$ & & $\begin{array}{l}\text { No preoperative } \\
\text { comparison, looked } \\
\text { only at postoperative } \\
\text { ODI/VAS }\end{array}$ & $\begin{array}{l}\text { Concluded that postoperative } \\
\text { VAS and ODI scores were } \\
\text { acceptable but could not } \\
\text { show a decrease compared } \\
\text { with preoperatively. }\end{array}$ & 3 implant malposition \\
\hline Total & 361 & & & & \\
\hline
\end{tabular}

Abbreviations: CT, computed tomography; N/A, not applicable; ODI, Oswestry Disability Index; RMD, Roland Morris Disability Scale; SI, sacroilial; VAS, visual analog scale.

occurred. CT scan at 1 year showed a high rate $(97 \%)$ of bone adherence to at least 2 implants on both the iliac and sacral sides, with modest rates of bone growth across the SI joint. Similarly, Darr et $\mathrm{al}^{33}$ report 3-year prospective follow-up in 103 patients participating in 2 US clinical trials. Patients had mean improvements in SI joint pain of 55 points (0-100 scale), mean improvement in ODI of 28 points, and improvement in EuroQOL-5D of 0.3 points (all $P<.0001$ ). There was 1 late revision. Four patients underwent contralateral SI joint fusion.

There are 2 level 1 prospective studies. The first, from Polly et al, ${ }^{34}$ reported 24-month outcomes of a prospective, randomized controlled trial comparing minimally invasive SI joint fusion using triangular titanium implants to nonoperative care. Nonsurgical care consisted of medication management, 
physical therapy, SI joint steroid injections, and radiofrequency ablation of lateral branches of sacral nerve roots, administered according to patient needs. Success - a composite of pain reduction, absence of serious adverse events or neurologic worsening, and absence of repeat surgery-occurred in $82 \%$ of the SI joint fusion group and $26 \%$ of the nonsurgical group. By month 24, 82\% received substantial clinical benefit (Glassman criteria $^{35}$ ) in VAS SI joint pain score, and $66 \%$ had received substantial clinical benefit in ODI score. In the nonsurgical group, these proportions were less than $10 \%$ with nonsurgical treatment only. Parallel changes were seen for EQ-5D and SF-36, with larger changes in the surgery group at 6 months compared with nonsurgical management. Three patients assigned to SI joint fusion underwent revision surgery within the 24-month follow-up period.

The second level 1 study, from Dengler et al, reported 12-month outcomes ${ }^{36}$ outcomes from a similarly designed prospective, multicenter randomized controlled surgery versus nonsurgery trial conducted in 9 centers in Europe. A total of 52 patients underwent SI joint fusion, and 51 patients underwent conservative management. At 6 months, mean low back pain improved by 43.3 points in the SI joint fusion group and 5.7 points in the conservative management group (difference of 38.1 points, $P<.0001)$. Mean ODI improved by 26 points in the SI joint fusion group and 6 points in the nonsurgical group $(P<.0001)$. ASLR, EQ-5D$3 \mathrm{~L}$, walking distance, and satisfaction were statistically superior in the SI joint fusion group. Improvements persisted at 12 months. The frequency of adverse events did not differ between groups. One case of postoperative nerve impingement occurred in the surgical group.

Lastly, SI-BONE, the manufacturer of triangular titanium implants, published 2 safety analyses from internal databases. First, Miller et $\mathrm{al}^{37}$ reported an analysis of the manufacturer's complaints database regarding use of the implants in 5319 patients. Complaints include any spontaneous or observed deficiency in the device. The complaint rate was $3.8 \%$. Nerve impingement $(0.9 \%)$ and pain unrelated to nerve impingement $(1.3 \%)$ were most common. Improper device placement occurred in 72 cases $(1.4 \%)$. There were 96 revision surgeries performed in 94 patients. Later, Cher et $\mathrm{al}^{38}$ reported an update from the same database with a greater number of patients ( $\mathrm{n}=11388$ procedures) in the hopes of calculating a surgical revision rate after SI joint fusion using triangular titanium implants. Implant survivorship at 4 years was $96.46 \%$, and revision rates went down every year, with revision rates after 2012 being approximately $2 \%$.

\section{Hydroxy-Appetite Coated Screw (Globus Medical)}

There is 1 level 2 study of hydroxy-appetite coated screws placed through an MIS lateral approach. Rappoport et $\mathrm{al}^{39}$ reported 24-month follow-up in 32 patients. Mean patient age was 55 years, and $63 \%$ were women. Leg pain and back pain VAS scores each statistically improved at 12-month follow-up. ODI improved from 55.6 to 34.6 at 12 months. Two patients underwent revision surgery for screw loosening. All patients who were working before surgery returned to work postoperatively within 3 months.

\section{Simmetry Implant}

The Simmetry implant (RTI Surgical, formerly Zyga Technologies) is a threaded titanium implant placed through a lateral minimally invasive approach. This system is US Food and Drug Administration-cleared for SI joint fusion. The system is unique in having associated devices to partially decorticate the joint prior to implant placement. $^{40}$

The evidence supporting this implant comes from retrospective case series and 1 level 2 prospective study. Cross et $\mathrm{al}^{41}$ report a retrospective case series of 19 patients at 3 centers with 2-year follow-up. Mean age was 60 years, and 79\% were women. SI joint pain improved from 7.9 at baseline to 2.1 at 24 months. There were no procedure complications. Four patients had device-related adverse events, but these were not described. Satisfaction rates were high at $94 \%$, and $89 \%$ would recommend the surgery to another. At 12 months $79 \%$ had bridging bone across the SI joint as interpreted by an independent reader.

Kube and Muir ${ }^{42}$ retrospectively reported 12month follow-up on 20 fusions done in 18 patients with the Simmetry implant. The fusion rate was $88 \%$. Back and leg pain improved from 81.7 to 44.1 points $(P<.001)$ and from 63.6 to 27.7 points $(P=.001)$, respectively. A total of 8 patients $(57 \%)$ achieved the minimum clinically important differ- 
ence in ODI score improvement at 12 months. No major complications were reported.

The level 2 prospective study was conducted by Araghi et $\mathrm{al}^{43}$ The authors report a trial of 50 patients who underwent SI joint fusion using Simmetry. Mean age was 62 years, and $58 \%$ were women. SI joint pain decreased from 76.2 at baseline to 35.1 (54\% reduction, $P<.0001)$. ODI decreased from 55.5 to 35.3 at 6 months $(P<.001)$. Opioid use decreased from $66 \%$ to $30 \%$. Two procedure-related events required hospitalization: a revision procedure $(2 \%)$ for nerve impingement and 1 case of ongoing low back pain.

\section{Hollow Modular Anchorage Screws}

A prospective study by Al-Khayer et $\mathrm{al}^{44}$ in 2008 reported results of 9 patients undergoing MIS sacroiliac fusion using a hollow modular anchorage screw filled with demineralized bone matrix and local bone that was obtained during drilling. The mean follow-up was 40 months (range, 24-70 months). The mean ODI value dropped from 59 (range, 34-70) preoperatively to 45 (range, 28-60) postoperatively $(P<.005)$, which we would interpret as a modest clinical improvement. The mean VAS value also modestly dropped from 8.1 (range, 7-9) preoperatively to 4.6 (range, 3-7) postoperatively $(P<.002)$. All of the patients reported that they would have the procedure again given the same circumstances. The average estimated blood loss was less than $50 \mathrm{~mL}$. There was 1 complication consisting of a deep wound infection that healed with debridement and intravenous antibiotics. At 1year follow-up, no nonunions were identified on radiographs.

In 2009, Khurana et $\mathrm{al}^{45}$ prospectively also reported on 15 consecutive patients treated with MIS fusion using hollow modular anchorage screws in combination with demineralized bone matrix. The mean follow-up in this study was 17 months (range, 9-39 months). The mean SF-36 scores improved from 37 (range, 23-51) to 80 (range, 6792) for physical function and from 53 (range, 34-73) to 86 (range, $70-98)$ for general health $(P=.037)$. A total of 13 of 15 patients reported "good to excellent" results. The authors reported that residual pain in these 2 patients was potentially due to concurrent lumbar pathology. The average estimated blood loss was less than $50 \mathrm{~mL}$, and there were no complications. Fusion was obtained in all patients.
In 2013, Mason et $\mathrm{al}^{46}$ reported a prospective case series of 55 patients undergoing SI joint fusion using hollow modular anchorage screws and demineralized bone matrix. It appears that all patients included in Khurana et $\mathrm{al}^{45}$ were also included in this report. Prior lumbar fusion was present in $40 \%$. Mean follow-up was 36 months. VAS SI joint pain improved from 8 to 4.5 at latest follow-up. SF-36 PCS improved from 26.6 to 42.9. Majeed score improved from 36.9 to 64.8 . Patients with previously instrumented spine surgery fared poorer with SI joint fusion compared with those without such a history.

\section{Pooled Outcomes}

For each study, we abstracted VAS and ODI data and conducted a pooled analysis. In some cases, the study reported a preoperative value but did not include postoperative data, or vice versa. In these cases, we included the available data points in the pooled analysis, even if one of the follow-up or preoperative data points was missing. Two studies had this type of incomplete reporting. Argahi et $\mathrm{al}^{43}$ reported mean and SD for ODI and VAS preoperatively, but no SD data were presented in follow-up. Rudolf et $\mathrm{al}^{20}$ did not report preoperative SD values.

Every available study reported a mean decrease in VAS, and the result was statistically significant for each study evaluated, and also in the pooled analysis (Figure 1). In addition, every study reported a mean decrease in ODI, and the result was statistically significant in every study except for Endres and Ludwig ${ }^{17}$ (Figure 2). The pooled analysis showed a mean decrease in VAS from 80.3 to 32.2 and the ODI showed a mean decrease from 56.2 to 34.4 , with both results being statistically significant $(P<.05$; Figure 3$)$.

\section{DISCUSSION}

Back pain remains one of the most common contributors to disability worldwide. Emerging evidence points to the SI joint as a pain generator, and numerous recent publications have reported on the outcomes of minimally invasive techniques for SI joint fusion. Overall, the quality of available evidence is mixed and in general consists of level 4 retrospective studies, with a scattering of some level 2 prospective studies, and only 2 level 1 prospective clinical trials. Nonetheless, multiple publications across multiple implant types report improved 
VAS Pain Score: 12-Month Follow-up* vs. Pre-operative

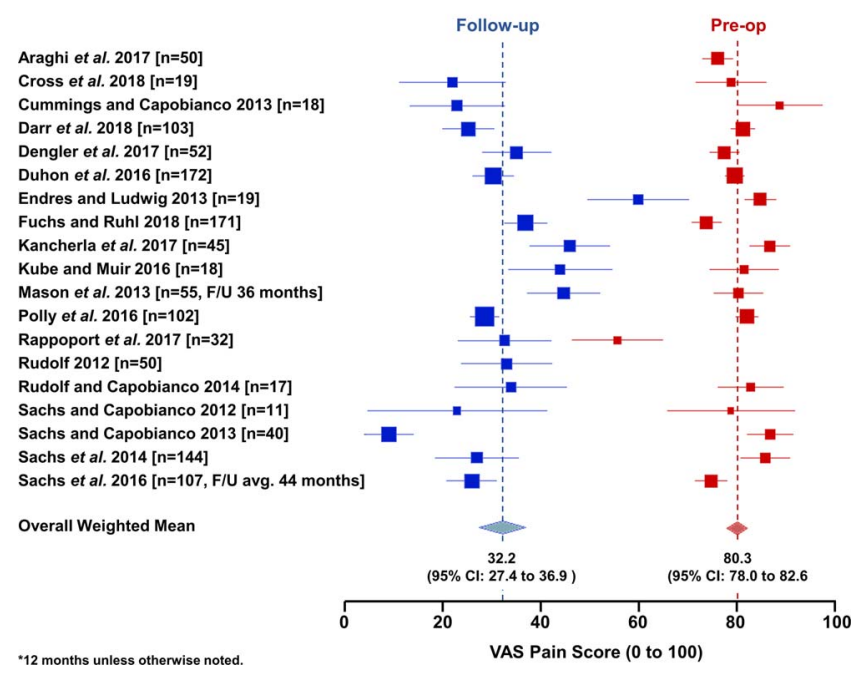

Figure 1. Forest plot showing preoperative and postoperative visual analog scale scores. The postoperative time point is 12 months unless otherwise noted for studies that did not provide 12-month data.

PROMs after surgery in most patients, with low complication rates.

Historically, surgeons have been reluctant to consider the SI joint as a pain generator. However, recent studies have shown that the SI joint moves (albeit only a little), ${ }^{7,8}$ it is innervated, ${ }^{9,10}$ and it becomes arthritic. Furthermore, the published studies identified here uniformly reported mean improvements in PROMs after SI joint fusion. This clinical improvement would seem to further support the SI joint as a pain generator. It seems reasonable to suggest that clinicians should regularly evaluate the SI joint as a part of their clinical exam in patients with low back pain.

Of note, the magnitude of clinical improvement seen across these studies is typically modest. In our pooled analysis, the mean ODI score decreased from 56.2 to 34.4 , which would indicate a moderate level of residual disability. This magnitude of decrease was roughly consistent across the studies with available data (Figure 2). Thus, it seems reasonable to counsel patients that although surgery can help, it is unlikely to take away all of their pain.

Furthermore, although the mean improvement in PROMs uniformly favored surgery, the individual response rate was not universal. For example, in the level 1 studies of triangular implants, $71 \%$ of patients $^{47}$ and $66 \%$ of patients ${ }^{34}$ reported clinically significant improvement in disability measures. These numbers would seem to indicate that a modest number of patients (perhaps as high as a quarter to one-third) did not respond to surgery, in

\section{Oswestry Disability Index: 12-Month Follow-up vs. Pre-operative}

Araghi et al. 2017 [ $n=50]$ Cummings and Capobianco 2013 [ $n=18$ ] Darr et al. 2018 [ $n=103$ ] Dengler et al. 2017 [ $n=52]$ Duhon et al. 2016 [ $n=172]$ Endres and Ludwig 2013 [ $n=19$ ] Fuchs and Ruhl 2018 [ $n=171]$ Kancherla et al. 2017 [ $n=45$ ] Kube and Muir 2016 [ $n=18]$ Polly et al. 2016 [ $n=102]$ Rappoport et al. 2017 [ $n=32]$

Overall Weighted Mean

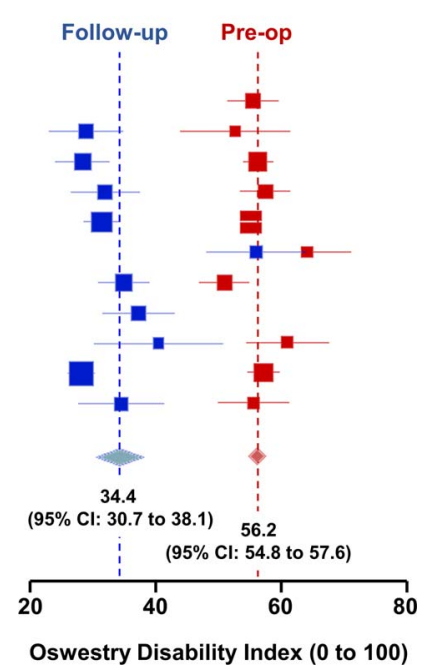

Figure 2. Forest plot showing preoperative and postoperative Oswestry Disability Index scores. The postoperative time point is 12 months unless otherwise noted for studies that did not provide 12-month data.

terms of improvement in disability. The reasons for this are likely multifactorial. It is possible that the disability measures do not fully capture the clinical benefit of the surgery. For example, a higher percentage of patients $(82 \%)$ in the Polly et $\mathrm{al}^{34}$ randomized study reported an improvement in SI joint pain scores, as compared with improvement in disability $(66 \%)$. These results match with the outcome of our pooled analysis, which showed better mean improvement in VAS scores as compared with ODI (Figure 3). Alternatively, patient selection and diagnostic accuracy may play a role.

Weighted Means of Visual Analog Scale Pain Score (VAS) and Oswestry Disability Index (ODI)

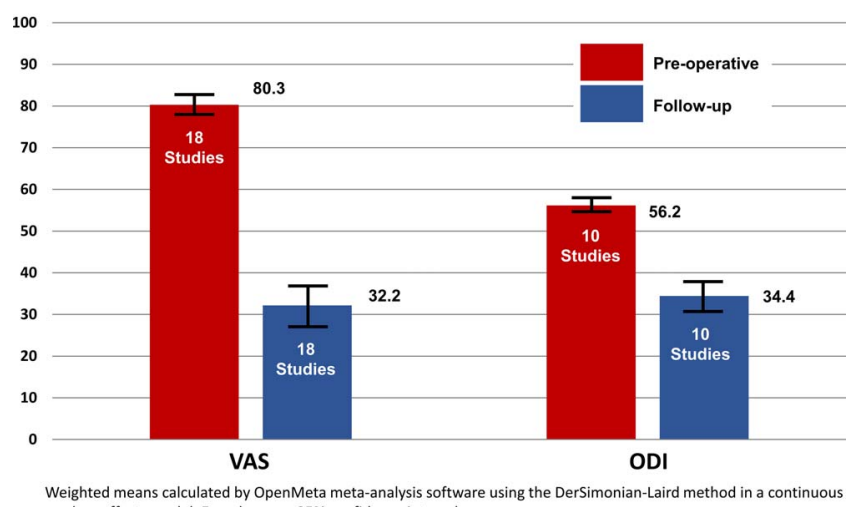

Weighted means calculated by OpenMeta meta-analysis software using the DerSimonian-Laird method in a continuous

Figure 3. Pooled analysis of weighted means for preoperative and postoperative visual analog scale and Oswestry Disability Index scores. The postoperative time point is 12 months, unless, as previously noted in Figures 1 and 2 , the studies did not provide 12-month data. 
The authors of this manuscript recommend that in order to be candidates for an MIS SI joint fusion, patients have at least 3 of 5 positive provocative exam maneuvers, ${ }^{48}$ report pain consistent with that coming from the SI joint with a positive Fortin finger sign, ${ }^{49}$ and have a positive response to diagnostic SI joint injections.

As a whole, these studies do carry some weaknesses. Most are supported by industry funding, potentially introducing bias into the reporting of results. In addition, the vast majority are level 4 retrospective series, and the overall quality of data is modest. The summary of the data provided here may prove useful in planning for future randomized studies that seek funding from nonindustry sources. Patient use of opioids is another important clinical outcome measure that was not addressed in this article, but the reporting of these data was quite variable across the studies, with most of the articles including no data available to reference. We feel that the limited data available precludes a pooled analysis, which was the focus of this study. Similarly, in this era of value-based health care, cost-effectiveness is an important benchmark, and several articles did address this topic. ${ }^{50-54}$ However, we feel that a thorough review of these articles is outside the scope of this manuscript. Lastly, the pooled analysis presented here is not meant to determine the superiority of one implant device or one approach compared with another. These types of conclusions would require head-to-head clinical trials, and we feel this would be an interesting avenue for additional research.

In summary, minimally invasive sacroiliac joint fusion provides clinically significant improvement in pain scores and disability in most patients, across multiple studies and implant manufacturers. Emerging evidence in support of the results from SI joint fusion surgery indicates that clinicians should examine the SI joint and include SI joint pain in their differential diagnosis for low back pain patients.

\section{REFERENCES}

1. Manchikanti L, Singh V, Datta S, Cohen SP, Hirsch JA; American Society of Interventional Pain P. Comprehensive review of epidemiology, scope, and impact of spinal pain. Pain Physician. 2009;12(4):E35-E70.

2. Martin BI, Deyo RA, Mirza SK, et al. Expenditures and health status among adults with back and neck problems. JAMA. 2008;299(6):656-664.

3. Martin BI, Turner JA, Mirza SK, Lee MJ, Comstock BA,
Deyo RA. Trends in health care expenditures, utilization, and health status among US adults with spine problems, 1997-2006. Spine (Phila Pa 1976). 2009;34(19):2077-2084.

4. Sembrano JN, Polly DW Jr. How often is low back pain not coming from the back? Spine (Phila Pa 1976). 2009;34(1):E27-E32.

5. Schwarzer AC, Aprill CN, Bogduk N. The sacroiliac joint in chronic low back pain. Spine (Phila Pa 1976). 1995;20(1):3137.

6. Albee FH. a study of the anatomy and the clinical importance of the sacroiliac joint. JAMA. 1909;53(16):12731276.

7. Vleeming A, Van Wingerden JP, Dijkstra PF, Stoeckart R, Snijders CJ, Stijnen T. Mobility in the sacroiliac joints in the elderly: a kinematic and radiological study. Clin Biomech (Bristol, Avon). 1992;7(3):170-176.

8. Sturesson B, Uden A, Vleeming A. A radiostereometric analysis of movements of the sacroiliac joints during the standing hip flexion test. Spine (Phila Pa 1976). 2000;25(3):364-368.

9. Vilensky JA, O'Connor BL, Fortin JD, et al. Histologic analysis of neural elements in the human sacroiliac joint. Spine (Phila Pa 1976). 2002;27(11):1202-1207.

10. Szadek KM, Hoogland PV, Zuurmond WW, de Lange JJ, Perez RS. Nociceptive nerve fibers in the sacroiliac joint in humans. Reg Anesth Pain Med. 2008;33(1):36-43.

11. Szadek KM, Hoogland PV, Zuurmond WW, De Lange JJ, Perez RS. Possible nociceptive structures in the sacroiliac joint cartilage: an immunohistochemical study. Clin Anat. 2010;23(2):192-198.

12. Polly DW, Cher D. Ignoring the sacroiliac joint in chronic low back pain is costly. Clinicoecon Outcomes Res. 2016;8:23-31.

13. Lorio MP, Polly DW Jr, Ninkovic I, Ledonio CG, Hallas $\mathrm{K}$, Andersson G. Utilization of minimally invasive surgical approach for sacroiliac joint fusion in surgeon population of ISASS and SMISS membership. Open Orthop J. 2014;8:1-6.

14. Smith AG, Capobianco R, Cher D, et al. Open versus minimally invasive sacroiliac joint fusion: a multi-center comparison of perioperative measures and clinical outcomes. Ann Surg Innov Res. 2013;7(1):14.

15. Ledonio CG, Polly DW Jr, Swiontkowski MF. Minimally invasive versus open sacroiliac joint fusion: are they similarly safe and effective? Clin Orthop Relat Res. 2014;472(6):1831-1838.

16. Ledonio CG, Polly DW Jr, Swiontkowski MF, Cummings JT Jr. Comparative effectiveness of open versus minimally invasive sacroiliac joint fusion. Med Devices (Auckl). 2014;7:187-193.

17. Endres S, Ludwig E. Outcome of distraction interference arthrodesis of the sacroiliac joint for sacroiliac arthritis. Indian J Orthop. 2013;47(5):437-442.

18. Wise CL, Dall BE. Minimally invasive sacroiliac arthrodesis: outcomes of a new technique. J Spinal Disord Tech. 2008;21(8):579-584.

19. Fuchs V, Ruhl B. Distraction arthrodesis of the sacroiliac joint: 2-year results of a descriptive prospective multi-center cohort study in 171 patients. Eur Spine J. 2018;27(1):194-204.

20. Rudolf L. Sacroiliac joint arthrodesis-MIS technique 
with titanium implants: report of the first 50 patients and outcomes. Open Orthop J. 2012;6:495-502.

21. Sachs D, Capobianco R. One year successful outcomes for novel sacroiliac joint arthrodesis system. Ann Surg Innov Res. 2012;6(1):13.

22. Rudolf L. MIS Fusion of the SI joint: does prior lumbar spinal fusion affect patient outcomes? Open Orthop J. 2013;7:163-168.

23. Sachs D, Capobianco R. Minimally invasive sacroiliac joint fusion: one-year outcomes in 40 patients. Adv Orthop. 2013;2013:536128.

24. Cummings J Jr, Capobianco RA. Minimally invasive sacroiliac joint fusion: one-year outcomes in 18 patients. Ann Surg Innov Res. 2013;7(1):12.

25. Gaetani P, Miotti D, Risso A, et al. Percutaneous arthrodesis of sacro-iliac joint: a pilot study. J Neurosurg Sci. 2013;57(4):297-301.

26. Schroeder JE, Cunningham ME, Ross T, Boachie-Adjei O. Early results of sacro-iliac joint fixation following long fusion to the sacrum in adult spine deformity. HSS J. 2014;10(1):30-35.

27. Sachs D, Capobianco R, Cher D, et al. One-year outcomes after minimally invasive sacroiliac joint fusion with a series of triangular implants: a multicenter, patient-level analysis. Med Devices (Auckl). 2014;7:299-304.

28. Rudolf L, Capobianco R. Five-year clinical and radiographic outcomes after minimally invasive sacroiliac joint fusion using triangular implants. Open Orthop J. 2014;8:375383.

29. Vanaclocha-Vanaclocha V, Verdú-López F, SánchezPardo M, et al. Minimally invasive sacroiliac joint arthrodesis: experience in a prospective series with 24 patients. $J$ Spine. 2014;3(185).

30. Sachs D, Kovalsky D, Redmond A, et al. Durable intermediate-to long-term outcomes after minimally invasive transiliac sacroiliac joint fusion using triangular titanium implants. Med Devices (Auckl). 2016;9:213-222.

31. Kancherla VK, McGowan SM, Audley BN, Sokunbi G, Puccio ST. Patient reported outcomes from sacroiliac joint fusion. Asian Spine J. 2017;11(1):120-126.

32. Duhon BS, Bitan F, Lockstadt H, et al. Triangular titanium implants for minimally invasive sacroiliac joint fusion: 2-year follow-up from a prospective multicenter trial. Int $J$ Spine Surg. 2016;10:13.22.

33. Darr E, Meyer SC, Whang PG, et al. Long-term prospective outcomes after minimally invasive trans-iliac sacroiliac joint fusion using triangular titanium implants. Med Devices (Auckl). 2018;11:113-121.

34. Polly DW, Swofford J, Whang PG, et al. Two-year outcomes from a randomized controlled trial of minimally invasive sacroiliac joint fusion vs. non-surgical management for sacroiliac joint dysfunction. Int J Spine Surg. 2016;10:28.

35. Glassman SD, Copay AG, Berven SH, Polly DW, Subach BR, Carreon LY. Defining substantial clinical benefit following lumbar spine arthrodesis. J Bone Joint Surg Am. 2008;90(9):1839-1847.

36. Dengler JD, Kools D, Pflugmacher R, et al. 1-year results of a randomized controlled trial of conservative management vs. minimally invasive surgical treatment for sacroiliac joint pain. Pain Physician. 2017;20(6):537-550.

37. Miller LE, Reckling WC, Block JE. Analysis of postmarket complaints database for the iFuse SI Joint Fusion System(R): a minimally invasive treatment for degenerative sacroiliitis and sacroiliac joint disruption. Med Devices (Auckl). 2013;6:77-84.

38. Cher DJ, Reckling WC, Capobianco RA. Implant survivorship analysis after minimally invasive sacroiliac joint fusion using the iFuse Implant System((R)). Med Devices (Auckl). 2015;8:485-492.

39. Rappoport LH, Luna IY, Joshua G. Minimally invasive sacroiliac joint fusion using a novel hydroxyapatite-coated screw: preliminary 1-year clinical and radiographic results of a 2-year prospective study. World Neurosurg. 2017;101:493-497.

40. Miller LE, Block JE. Minimally invasive arthrodesis for chronic sacroiliac joint dysfunction using the SImmetry SI Joint Fusion system. Med Devices (Auckl). 2014;7:125-130.

41. Cross WW, Delbridge A, Hales D, Fielding LC. Minimally invasive sacroiliac joint fusion: 2-year radiographic and clinical outcomes with a principles-based SIJ fusion system. Open Orthop J. 2018;12:7-16.

42. Kube RA, Muir JM. Sacroiliac joint fusion: one year clinical and radiographic results following minimally invasive sacroiliac joint fusion surgery. Open Orthop J. 2016;10:679-689.

43. Araghi A, Woodruff R, Colle K, et al. Pain and opioid use outcomes following minimally invasive sacroiliac joint fusion with decortication and bone grafting: the Evolusion clinical trial. Open Orthop J. 2017;11:1440-1448.

44. Al-Khayer A, Hegarty J, Hahn D, Grevitt MP. Percutaneous sacroiliac joint arthrodesis: a novel technique. $J$ Spinal Disord Tech. 2008;21(5):359-363.

45. Khurana A, Guha AR, Mohanty K, Ahuja S. Percutaneous fusion of the sacroiliac joint with hollow modular anchorage screws: clinical and radiological outcome. $J$ Bone Joint Surg Br. 2009;91(5):627-631.

46. Mason LW, Chopra I, Mohanty K. The percutaneous stabilisation of the sacroiliac joint with hollow modular anchorage screws: a prospective outcome study. Eur Spine J. 2013;22(10):2325-2331.

47. Sturesson B, Kools D, Pflugmacher R, Gasbarrini A, Prestamburgo D, Dengler J. Six-month outcomes from a randomized controlled trial of minimally invasive SI joint fusion with triangular titanium implants vs conservative management. Eur Spine J. 2017;26(3):708-719.

48. Szadek KM, van der Wurff $P$, van Tulder MW, Zuurmond WW, Perez RS. Diagnostic validity of criteria for sacroiliac joint pain: a systematic review. $J$ Pain. 2009;10(4):354-368.

49. Fortin JD, Falco FJ. The Fortin finger test: an indicator of sacroiliac pain. Am J Orthop (Belle Mead NJ). 1997;26(7):477-480.

50. Ackerman SJ, Polly DW Jr, Knight T, Schneider K, Holt $\mathrm{T}$, Cummings J Jr. Comparison of the costs of nonoperative care to minimally invasive surgery for sacroiliac joint disruption and degenerative sacroiliitis in a United States commercial payer population: potential economic implications of a new minimally invasive technology. Clinicoecon Outcomes Res. 2014;6:283-296.

51. Ackerman SJ, Polly DW Jr, Knight T, Holt T, Cummings J. Management of sacroiliac joint disruption and degenerative sacroiliitis with nonoperative care is medical resource-intensive and costly in a United States commercial payer population. Clinicoecon Outcomes Res. 2014;6:63-74. 
52. Ackerman SJ, Polly DW, Jr., Knight T, Holt T, Cummings J, Jr. Nonoperative care to manage sacroiliac joint disruption and degenerative sacroiliitis: high costs and medical resource utilization in the United States Medicare population. $J$ Neurosurg Spine. 2014;20(4):354-363.

53. Ackerman SJ, Polly DW Jr, Knight T, Schneider K, Holt $\mathrm{T}$, Cummings J. Comparison of the costs of nonoperative care to minimally invasive surgery for sacroiliac joint disruption and degenerative sacroiliitis in a United States Medicare population: potential economic implications of a new minimallyinvasive technology. Clinicoecon Outcomes Res. 2013;5:575587.

54. Cher DJ, Frasco MA, Arnold RJ, Polly DW. Costeffectiveness of minimally invasive sacroiliac joint fusion. Clinicoecon Outcomes Res. 2016;8:1-14.

Disclosures and COI: Each author certifies that he or she has no commercial associations (eg, consultancies, stock ownership, equity interest, patent/licensing arrangements) that might pose a conflict of interest in connection with the submitted work. This paper is exempt from institutional review board review because it is not human subjects research. There was no external source of funding for this study.

Corresponding Author: Christopher T. Martin, MD, Department of Orthopaedic Surgery, University of Minnesota, 2450 Riverside Avenue South, Suite R200, Minneapolis, MN 55454. Phone: (612) 273-8091; Email: mart1865@umn.edu.

Published 10 February 2020

This manuscript is generously published free of charge by ISASS, the International Society for the Advancement of Spine Surgery. Copyright (c) 2020 ISASS. To see more or order reprints or permissions, see http://ijssurgery.com. 